TITLE:

\title{
Expansion of tetrachloroaluminate- graphite intercalation compound by reaction with anhydrous hydrogen fluoride
}

$\operatorname{AUTHOR}(\mathrm{S}):$

Matsumoto, Kazuhiko; Minori, Daisuke; Takagi, Kosuke; Hagiwara, Rika

\section{CITATION:}

Matsumoto, Kazuhiko ... [et al]. Expansion of tetrachloroaluminate-graphite intercalation compound by reaction with anhydrous hydrogen fluoride. Carbon 2014, 67: 434-439

\section{ISSUE DATE:}

2014-02

URL:

http://hdl.handle.net/2433/182045

\section{RIGHT:}

(C) 2013 Elsevier Ltd.; This is not the published version. Please cite only the published version.; この論文は出版社版でありません。引用の際に は出版社版をご確認ご利用ください。 


\title{
Expansion of tetrachloroaluminate-graphite intercalation compound by reaction with anhydrous hydrogen fluoride
}

\author{
Kazuhiko Matsumoto*, Daisuke Minori, Kosuke Takagi, Rika Hagiwara
}

Graduate School of Energy Science, Kyoto University, Yoshida, Sakyo-ku, Kyoto 606-8501, Japan

*Corresponding author: Tel: +81-75-753-4817, E-mail: k-matsumoto@energy.kyoto-u.ac.jp (K. Matsumoto) 


\begin{abstract}
Reaction of the stage-1 graphite tetrachloroaluminate intercalation compound prepared from highly oriented pyrolytic graphite with anhydrous HF yields expanded graphite. According to scanning electron microscopy, exfoliation of graphite layers occurs more intensely as the reaction temperature increases. X-ray diffraction shows the expanded graphite has low crystallinity and the layer structure of graphite is highly disordered. X-ray photoelectron spectroscopy confirms formation of $\mathrm{AlF}_{3}$ and absence of $\mathrm{Cl}$ and covalent $\mathrm{C}-\mathrm{F}$ bonds. Infrared spectroscopy reveals the gaseous species released during the expansion are $\mathrm{HCl}$ and $\mathrm{CF}_{4}$. These observations suggest the following reaction is the source of the expansion: $\mathrm{C}_{\mathrm{x}} \mathrm{AlCl}_{4(s)}+4 \mathrm{HF}_{(l)} \rightarrow(\mathrm{x}-0.25) \mathrm{C}_{(s)}+\mathrm{AlF}_{3(s)}$ $+4 \mathrm{HCl}_{(g)}+0.25 \mathrm{CF}_{4(g)}$.
\end{abstract}




\section{Introduction}

Expansion of graphite occurs by separating graphite layers which are bound by van der Waals interactions each other. A number of methods have been reported to expand graphite, including thermal expansion and electrochemical expansion [1-3]. The graphite layers in usual expanded graphites are not completely exfoliated and a certain stacked structure is confirmed by diffraction techniques, which is reflected to their relatively low surface area $\left(<100 \mathrm{~m}^{2} \mathrm{~g}^{-1}\right)[3,4]$. Such materials have a wide range of applications including gaskets, thermal insulator, radiator, and electromagnetic interference shields, owing to its light weight, workability, and high thermal and chemical durability $[2,3]$. Nowadays, expanded graphite also attracts attention because it is often a good source of graphene materials which have a variety of applications such as catalyst supports, electronic devices, and energy storage in batteries and supercapacitors [5-7].

Thermal expansion is one of the most popular methods to expand graphite and graphite intercalation compounds (GICs) are often used as starting materials for this purpose $[1,8,9]$. Graphite intercalation compounds with sulfuric acid are typically used for industrial applications, but other GICs such as the ones with chlorometallate anions are also expanded by rapid heating. The driving force of the expansion is gas evolution from the intercalant between graphite layers involved with the decomposition of the GICs. The decomposition rate has to surpass the diffusion rate of the evolved gas to overcome the van der Waals interaction between graphite layers. Sudden heating to high temperature $\left(>1000{ }^{\circ} \mathrm{C}\right)$ is usually conducted for expansion of GICs, but low temperature treatment $\left(<1000{ }^{\circ} \mathrm{C}\right)$ also gives expanded graphite including reversible expansion in certain conditions $[10,11]$. Thermal treatment of GICs under vacuum also 
facilitates expansion of graphite layers [12].

GICs are formed by intercalation of guest species into graphite layers and are classified into two types; acceptor-type and donor-type, where the accepter-type GIC is formed by oxidation of graphite and the donor-type compound is formed by reduction of graphite [13]. One of the most well-studied acceptor-type GICs is the chlorometallate compound such as $\mathrm{AlCl}_{3}$ - and $\mathrm{FeCl}_{3}$-GIC [14-16]. Although reactivity of various chlorometallate-GICs has been studied [13], little is known about the reaction of chloroaluminate GICs with anhydrous HF (aHF), which is surprising, considering the long history of GICs with fluoride ion and various fluoroanions that have unique and useful properties $[13,17-19]$. In our study on the reactivity of chlorometallate GIC and aHF, we found the reaction of $\mathrm{AlCl}_{3}$-GIC and aHF resulted in the layer expansion of the GIC. The present study reports the reactivity of $\mathrm{AlCl}_{3}$-GIC with aHF at different temperatures and characterization of the products by X-ray diffraction (XRD), X-ray photospectroscopy (XPS), scanning electron microscopy (SEM), infrared spectroscopy (IR), and Raman spectroscopy.

\section{Experimental}

\subsection{Apparatus and Materials.}

Volatile materials were handled in a vacuum line constructed of SS-316 stainless steel and PFA (tetrafluoroethylene-perfluoroalkylvinylether copolymer) [20]. Nonvolatile materials were handled under a dry Ar atmosphere in a glove box. Anhydrous $\mathrm{HF}$ (Daikin Industries) was dried over $\mathrm{K}_{2} \mathrm{NiF}_{6}$ (Ozark-Mahoning Co.) prior to use. Anhydrous aluminum chloride (Wako Pure Chemical Industries, Ltd. purity, 99.9\%), Highly oriented pyrolytic graphite (HOPG) (STM-1, Advanced Ceramics 
Corp.), and chlorine gas (Sumitomo Seika Chemicals Co., Ltd.) were used as purchased. The stage- $1 \mathrm{AlCl}_{3}$-GIC was prepared by the reaction of aluminum chloride $\left(\mathrm{AlCl}_{3}\right)$, chlorine gas and the graphite as described in a previous work [15].

\subsection{Reaction of $\mathrm{AlCl}_{3}-\mathrm{GIC}$ with anhydrous $\mathrm{HF}$.}

The $\mathrm{AlCl}_{3}$-GIC compound was weighed $(0.090 \mathrm{~g}, 0.27 \mathrm{mmol})$ and loaded in a PFA reactor under the dry Ar condition. A large excess of aHF was distilled onto the $\mathrm{AlCl}_{3}$-GIC under vacuum at $-196^{\circ} \mathrm{C}$ and the reactor was slowly warmed up to the reaction temperature (room temperature, $-30{ }^{\circ} \mathrm{C}$, and $-80{ }^{\circ} \mathrm{C}$ ). The pressure inside the vessel had to be monitored until the reaction completely ceased because the byproduct $\mathrm{HCl}$ may increase the pressure inside. After the reaction for $6 \mathrm{~h}$ at the target temperatures, volatile gases were eliminated by evacuation through a soda lime chemical trap at first and through a liquid nitrogen trap at the final stage $(\sim 1 \mathrm{~Pa})$. Caution: Handling of aHF must be carefully performed using appropriate protective gear with immediate access to proper treatment procedures in the accident of contact with liquid HF, HF vapor, or HF-containing compounds. [21].

\subsection{Analysis.}

Powder XRD was performed by Ultima IV X-ray diffractometer (Rigaku Corp., $\mathrm{Cu}-\mathrm{K} \alpha$ radiation, $40 \mathrm{kV}-40 \mathrm{~mA}$ ). Air sensitive samples were loaded in an airtight cell with Be windows in the glove box. XPS analysis was performed by JPS-9010 MC (JEOL, Ltd.) with $\mathrm{MgK \alpha}$ radiation. Scanning rate was $0.25 \mathrm{eV} \mathrm{s}^{-1}$. Samples were fixed on carbon sheets. Before measurement, the surface of the samples were etched by Ar ion bombardment for $15 \mathrm{~s}$. Cross sectional microscopic observation of the samples was performed by VE-8800 scanning electron microscope (KEYENCE Corp.). IR spectra of the samples were obtained by a FTS-155 spectrometer (BIO-RAD Laboratories, Inc.) at 
room temperature. Gas samples were introduced into an airtight cell with a pair of $\mathrm{AgCl}$ crystal windows through the vacuum line. Raman spectra were obtained using the 633 $\mathrm{nm}$ line of a He-Ne laser as an excitation line (Nanofinder 30, Tokyo Instrument) at room temperature. Surface area was determined by the Brunauer-Emmett-Teller (BET) theory with nitrogen gas using TriStarII 3020 surface area analyzer (Micromeritics Instrument Corp.). Elemental analysis was performed at the Elemental Analysis Center in Institute for Chemical Research, Kyoto University.

\section{Results and discussion}

\subsection{Reactivity of $\mathrm{AlCl}_{3}$-GIC and anhydrous hydrogen fluoride}

The $\mathrm{AlCl}_{3}$-GIC compound prepared from $\mathrm{HOPG}$ was reacted with aHF at three different temperatures, $25,-30$, and $-80{ }^{\circ} \mathrm{C}$ and the products of these reactions are abbreviated as $\mathrm{EG}(25), \mathrm{EG}(-30)$, and $\mathrm{EG}(-80)$. In contrast to our expectation, this reaction did not result in formation of tetrafluoroaluminate-GIC $[22,23]$ but in formation of expanded graphite. During the reaction, bubbles, which were clearly visible in aHF, were generated from surface of $\mathrm{AlCl}_{3}$-GIC at all the reaction temperatures. For $\mathrm{EG}(25)$, the $\mathrm{AlCl}_{3}$-GIC piece was at the bottom of the reactor at the beginning of the reaction but floated up to the surface of aHF as the reactor was warmed up to room temperature and the reaction proceeded. On floating up, volume of the piece drastically increased. Fig. 1 shows the appearance of the expanded HOPG (EG(25)) obtained after the volatiles were removed (see Fig. S1 in Supplementary data for comparison of the HOPG samples in the PFA reactor before and after the reactions). The HOPG platelet of the starting $\mathrm{AlCl}_{3}$-GIC expanded into a typical worm-like shape. The appearance of $\mathrm{EG}(-30)$ was similar to that of $\mathrm{EG}(25)$, although the expansion occurred 
more slowly. In the case of the reaction at $-80{ }^{\circ} \mathrm{C}$, bubbles were observed in the first few minutes and the sample slightly expanded without floating. However, it expanded during warming up to room temperature after complete evacuation of aHF at $-80{ }^{\circ} \mathrm{C}$. This behavior suggests that the residual $\mathrm{HF}$ in the $\mathrm{AlCl}_{3}$-GIC gallery reacts with the GIC during warming up to room temperature. Although the degree of expansion for EG(-80) was smaller than those for $\mathrm{EG}(25)$ and $\mathrm{EG}(-30)$, the surface of the sample became rough like those at the other temperatures. Unique bluish black color of the stage- $1 \mathrm{AlCl}_{3}$-GIC slightly remained on the sample in this case. Nitrogen adsorption measurement showed the BET surface area of the most expanded EG(25) was $22 \mathrm{~m}^{2} \mathrm{~g}^{-1}$. This value is smaller than those for typical thermally expanded graphites $\left(\sim 40 \mathrm{~m}^{2} \mathrm{~g}^{-1}\right)$ and much smaller than the theoretical one $\left(2630 \mathrm{~m}^{2} \mathrm{~g}^{-1}\right)$ for the ideal graphene sheet [3, 4].

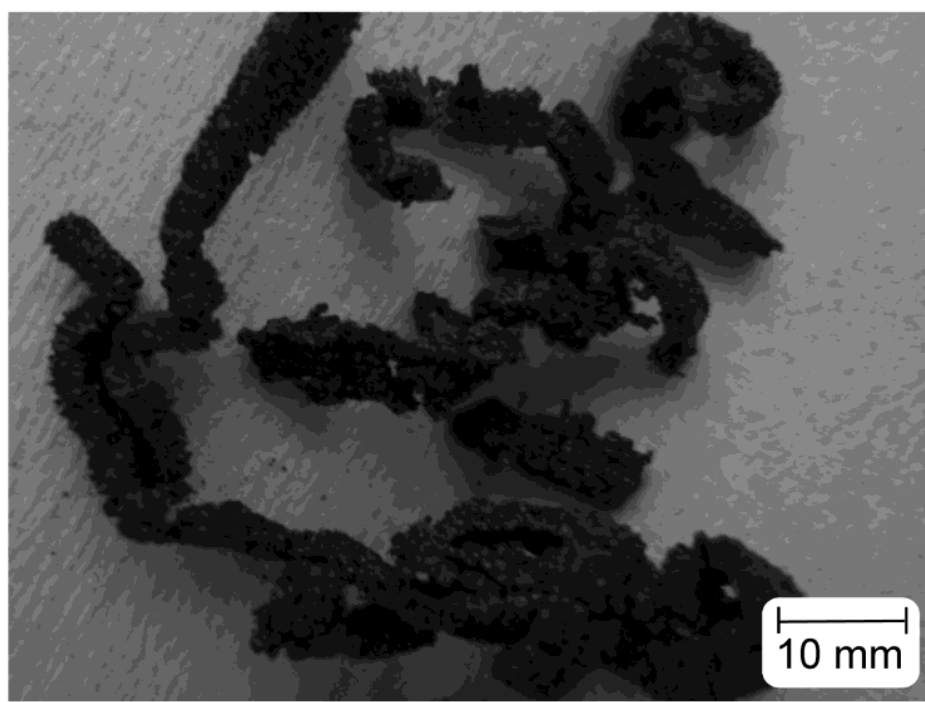

Fig. 1 A photograph of EG(25). 
Although the expansion may occur from the edge of HOPG involving the enlargement of the interlayer distance, intercalation of HF molecule in the GIC gallery at low temperature (Note: aHF turns liquid at $-84{ }^{\circ} \mathrm{C}$ during warming from liquid nitrogen temperature to the reaction temperature) followed by sudden expansion of graphite layers on warming is also a possible reaction way.

\subsection{Structure of the expanded graphite}

Fig. 2 shows the XRD patterns of EG(25), EG(-30), and EG(-80). The EG(25) and EG(-30) give only a broad peak around $25.7^{\circ}(d=3.47 \AA)$ and $26.1^{\circ}(d=3.41 \AA)$, respectively, indicating their highly disordered structures compared to the crystalline graphite structure $(d=3.35 \AA$ ). This structural change means that the layered structure of the stage- $1 \mathrm{AlCl}_{3}$-GIC was completely destroyed during the expansion of the graphite layers. The XRD pattern of EG(-80) differs from the other two cases and suggests that the product is the mixture of the expanded HOPG $\left(2 \theta=25.7^{\circ}, d=3.47 \AA\right)$ and the stage- $1 \mathrm{AlCl}_{3}$-GIC precursor with the repeating distance of $9.50 \AA\left(2 \theta=18.76^{\circ}[d=\right.$ $4.73 \AA$, the 002 diffraction peak $]$ and $2 \theta=28.04^{\circ}[d=3.18 \AA$, the 003 diffraction peak $\left.]\right)$ (see Fig. S5 in Supplementary data for details on the structures of the starting $\mathrm{AlCl}_{3}$-GIC) [8]. By taking into account the generation of bubbles, the reaction at $-80^{\circ} \mathrm{C}$ proceeded only at the surface of the $\mathrm{HOPG}$ piece and the stage- $1 \mathrm{AlCl}_{3}$-GIC still remains inside because of the slow reaction rate.

Fig. 3 shows SEM images of EG(25), EG(-30), and EG(-80) (see Figs. S2-S4 for SEM images at different magnifications). For the significantly expanded samples $(\mathrm{EG}(25)$ and $\mathrm{EG}(-30))$, the graphite layers are clearly exfoliated on the whole like a leaf. 
The edge of each exfoliated layer of $\mathrm{EG}(25)$ appears rougher than that of $\mathrm{EG}(-30)$, reflecting the vigorous reaction at the higher reaction temperature. On the other hand,

(a)

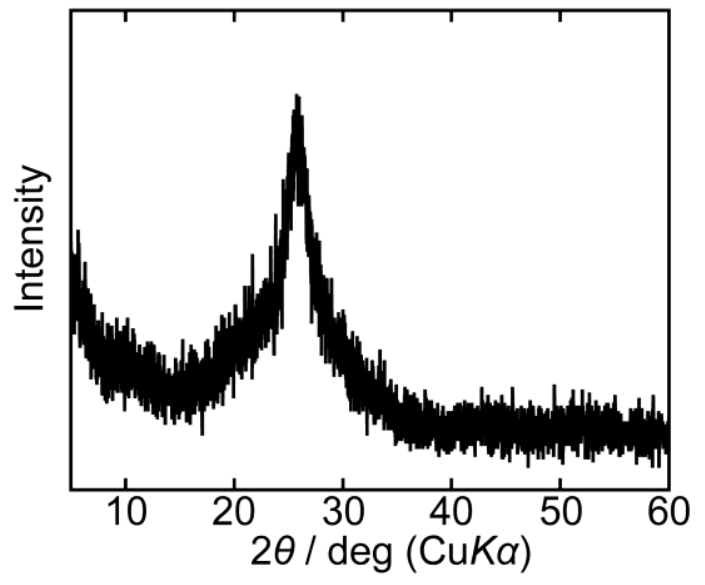

(b)

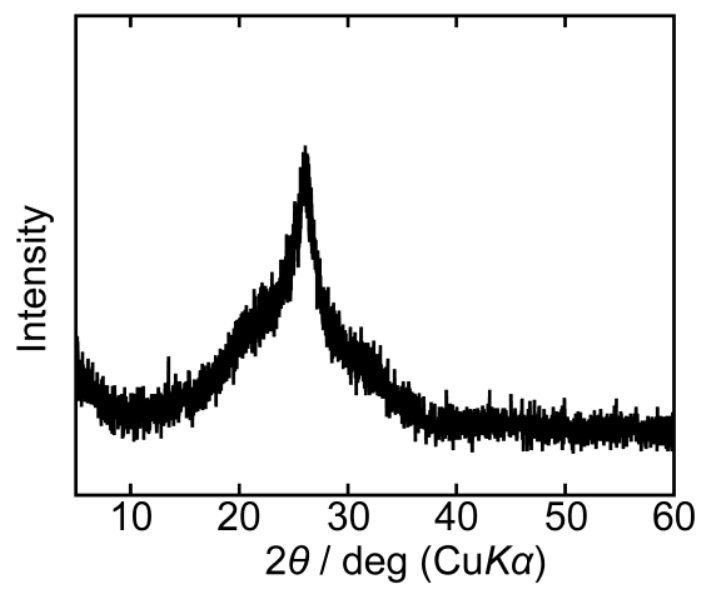

(c)

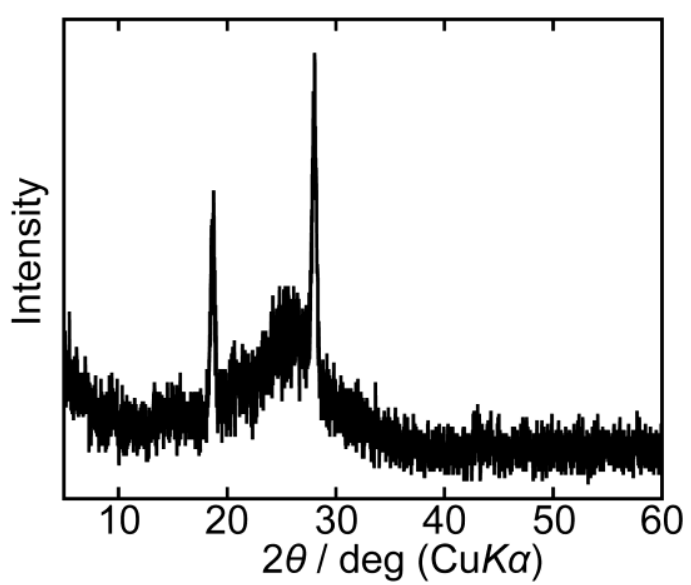

Fig. 2 XRD patterns of (a) EG(25), (b) EG(-30), and (c) EG(-80). 

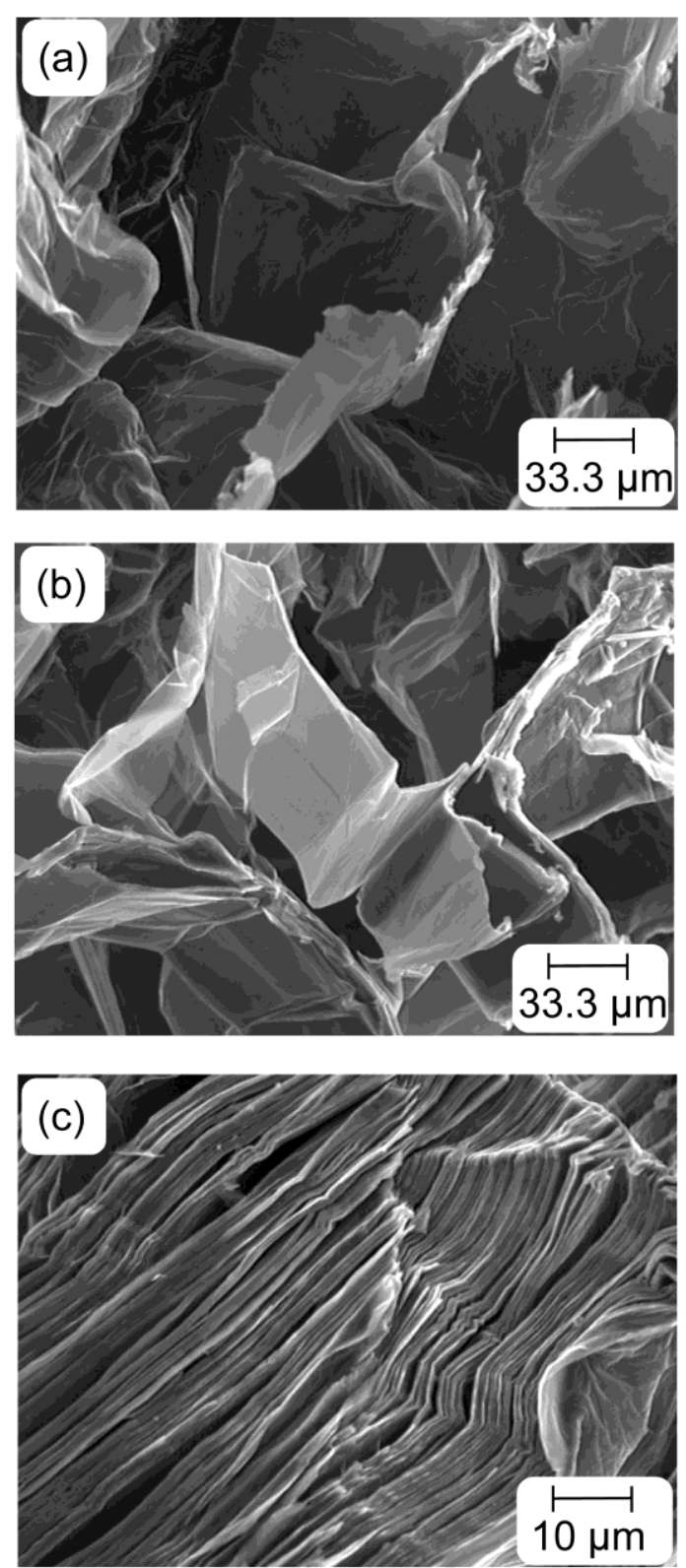

Fig. 3 SEM images of (a) EG(25), (b) EG(-30), and (c) EG(-80). 
EG(-80), which visually less expanded than EG(25) and EG(-30), exhibits gaps between the layers at intervals of $0.1 \sim 5 \mu \mathrm{m}$ but the degree of exfoliation is limited.

Fig. 4 shows C1s, F1s, A12 $p_{3 / 2}$, and Cl2 $p_{3 / 2}$ XPS spectra of EG(25), EG(-30), and $\mathrm{EG}(-80)$. The C1s spectra obtained for all the samples show a peak at $284.7 \mathrm{eV}$, corresponding to the $\mathrm{C}-\mathrm{C}$ bonds in graphite or $\mathrm{AlCl}_{3}-\mathrm{GIC}$, which indicates that strong C-F bonds (> $290 \mathrm{eV}$ ) is not dominant in this product $[24,25]$. The binding energies of the peaks in the F1s $(686.7,686.4$, and $686.7 \mathrm{eV}$ for $\mathrm{EG}(25)$, EG(-30), and $\mathrm{EG}(-80)$, respectively) and $\mathrm{Al} 2 \mathrm{p}_{3 / 2}(76.0,75.8$, and $75.8 \mathrm{eV}$ for $\mathrm{EG}(25), \mathrm{EG}(-30)$, and $\mathrm{EG}(-80)$, respectively) spectra are slightly lower than those for pure $\mathrm{AlF}_{3}(687.8$ and $76.5 \mathrm{eV}$ in the F1s and Al2 $\mathrm{p}_{3 / 2}$ spectra, respectively) [26, 27]. As was confirmed by the XRD pattern (Fig. 2), $\mathrm{AlF}_{3}$ produced by the present reaction is not crystallized and the environment around aluminium in the product may be different from that in the crystalline $\mathrm{AlF}_{3}$. The $\mathrm{Cl} 2 \mathrm{p}_{3 / 2}$ spectrum has a clear peak only in the case of $\mathrm{EG}(-80)$, which agrees with the XRD pattern containing the residual $\mathrm{AlCl}_{3}-\mathrm{GIC}$.

Typical Raman spectra of EG(25), EG(-30), EG(-80), and HOPG (basal plane) in the range of $1000-2000 \mathrm{~cm}^{-1}$ are shown in Fig. 5 where the first order Raman scatterings of graphite (and graphite-like carbon materials) are observed. Raman spectra of graphite and graphite-like carbon materials in this range are usually characterized by D-band $\left(\sim 1360 \mathrm{~cm}^{-1}\right)$, G-band $\left(\sim 1580 \mathrm{~cm}^{-1}\right)$, and D'-band $\left(\sim 1620 \mathrm{~cm}^{-1}\right)$; the G-band originates from the ordered graphene structure whereas the D- and D'-bands appear as structural disorders increase in the graphene sheet [28]. The spectrum of HOPG shows only one sharp peak at $1582 \mathrm{~cm}^{-1}$ because HOPG has highly oriented graphene sheets with little disorders. In the cases of $\mathrm{EG}(25)$ and $\mathrm{EG}(-30)$, the G-band is broad and the contribution of D'-band around $1620 \mathrm{~cm}^{-1}$ is indicated. The D-band observed around 
$1330 \mathrm{~cm}^{-1}$ for $\mathrm{EG}(25)$ and $\mathrm{EG}(-30)$ is much broader than the G- and D' bands. These results suggest a highly disordered structure of EG(25) and EG(-30) compared to the starting HOPG. Although the Raman spectrum of EG(-80) has a high dependency on the position, the D-band is very weak or not observed in many cases, which agrees with the observation during the reactions, that is, the degree of expansion for $E G(-80)$ is smaller than those of $\mathrm{EG}(25)$ and $\mathrm{EG}(-30)$.
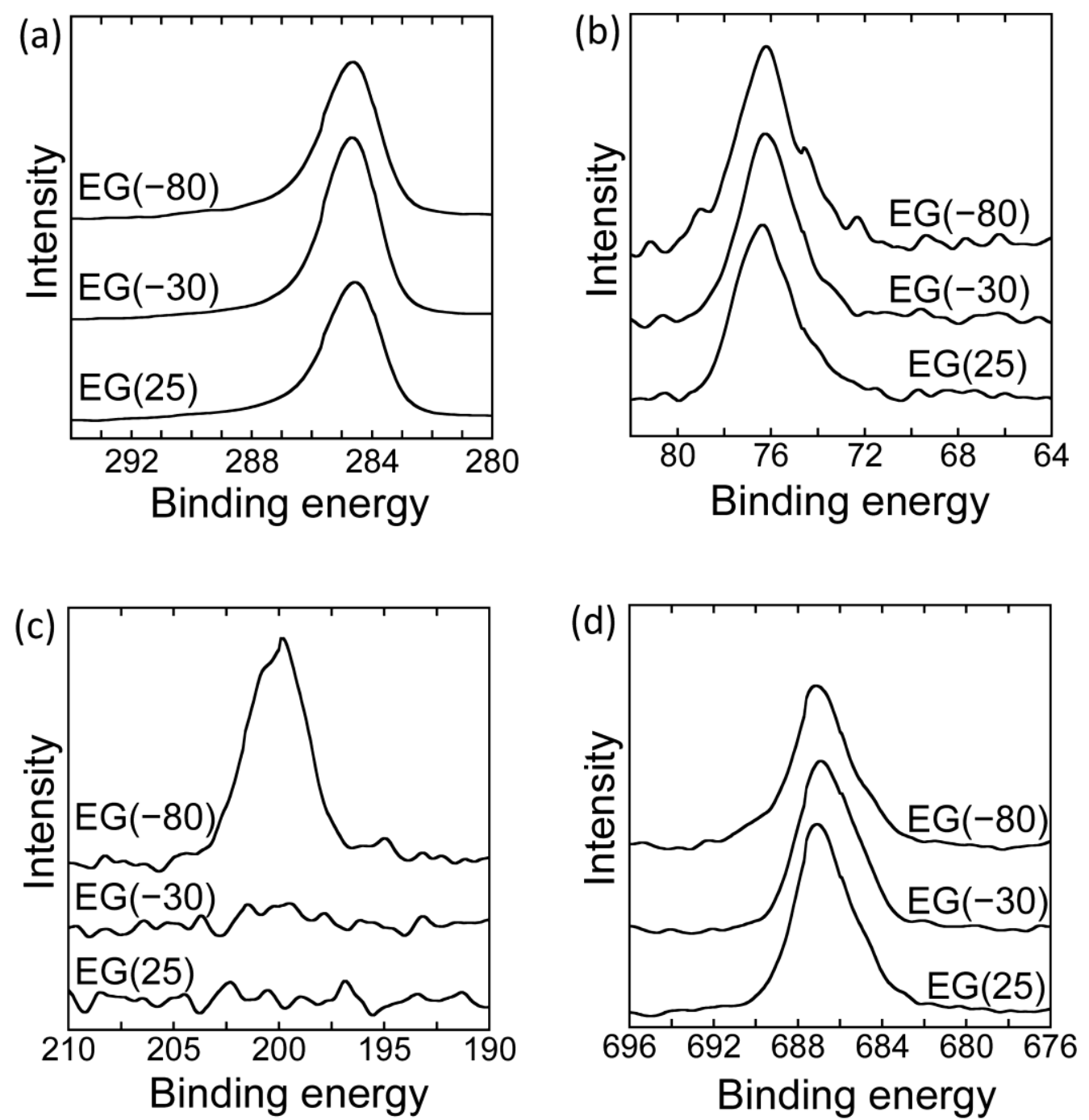

Fig. 4 (a) C1s, (b) Al2 $\mathrm{p}_{3 / 2}$, (c) Cl2 $\mathrm{p}_{3 / 2}$, and (d) F1s XPS spectra of EG(25), EG(-30), and $\mathrm{EG}(-80)$. 


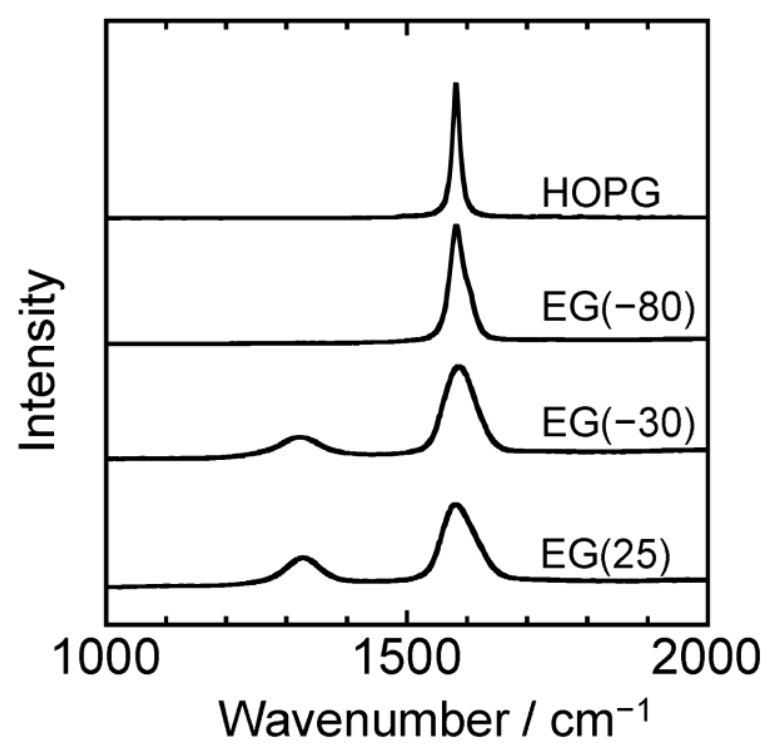

Fig. 5 Raman spectrum of EG(25), EG(-30), EG(-80), and HOPG (basal plane) in the range between 1000 and $2000 \mathrm{~cm}^{-1}$.

\subsection{Mechanism of formation of the expanded graphite}

In general, expansion of graphite materials by heat-treatment of GICs occurs along the $c$-axis of graphite. During expansion, the intercalant (and sometimes accompanied by water co-intercalated) in the GICs vaporize and widen the space between graphite layers. The present case of the reaction between $\mathrm{AlCl}_{3}$-GIC and aHF apparently involves halogen exchange between chlorine and fluorine, but the absence of $\mathrm{C}-\mathrm{F}$ covalent bonds and $\mathrm{C}_{x} \mathrm{~F}$ carbon fluorides in the resulting expanded graphite suggests that the anionic species is oxidized and fluorine atom is removed as a certain gaseous species. The stage- $3 \mathrm{C}_{x} \mathrm{AlF}_{4}$ with cointercalated $\mathrm{CH}_{3} \mathrm{NO}_{2}$ molecules is electrochemically formed in a previous work and is stable for a while [23]. The difference between the present case and the electrochemically formed stage- $3 \mathrm{C}_{x} \mathrm{AlF}_{4}$ might arise from the stage number because the present reaction started from stage- $1 \mathrm{AlCl}_{3}$-GIC and graphite layers 
could not hold such a lot of resulting $\mathrm{AlF}_{4}^{-}$inside.

Fig. 6 shows the IR spectrum of the gaseous products for the reaction between $\mathrm{AlCl}_{3}$-GIC and aHF at $25^{\circ} \mathrm{C}$. In addition to the $\mathrm{H}-\mathrm{Cl}$ stretching band around $2900 \mathrm{~cm}^{-1}$ [29], the $v_{3}\left(1281 \mathrm{~cm}^{-1}\right.$, asymmetric stretching $\left.\left(F_{2}\right)\right)$ and $v_{4}\left(631 \mathrm{~cm}^{-1}\right.$, asymmetric bending $\left(F_{2}\right)$ ) modes of $\mathrm{CF}_{4}$ as well as the $2 v_{4}$ overtone at $1256 \mathrm{~cm}^{-1}$ are observed in this spectrum. This suggests that the main reaction occurring during the expansion is:

$$
\mathrm{C}_{\mathrm{x}} \mathrm{AlCl}_{4(s)}+4 \mathrm{HF}_{(l)} \rightarrow(x-0.25) \mathrm{C}_{(s)}+\mathrm{AlF}_{3(s)}+4 \mathrm{HCl}_{(g)}+0.25 \mathrm{CF}_{4(g)}
$$

Although evolution of $\mathrm{HCl}$ gas can cause expansion of the $\mathrm{GIC}$, formation of $\mathrm{CF}_{4}$ breaks the carbon frame of the GIC and accelerates it. Destruction of the carbon frame is not peculiar for the present case. For example, IR spectroscopic analysis of the gaseous products suggests a part of the carbon frame in graphite oxide is consumed as $\mathrm{CO}_{2}$ during thermal expansion and the weight loss of the graphite oxide reaches $30 \%$ of the original sample [30]. The very weak white color around the present expanded graphite may be caused by $\mathrm{AlF}_{3}$ whereas particles in a micrometer order were not confirmed in SEM images probably because the produced $\mathrm{AlF}_{3}$ is spread in and on the expanded graphite. As described above, the $\mathrm{AlCl}_{3}$-GIC slightly expanded at $-80{ }^{\circ} \mathrm{C}$ in aHF and more significantly expanded during warming up to room temperature after evacuation of volatiles at $-80^{\circ} \mathrm{C}$. By considering the melting points of $\mathrm{HCl}\left(-85^{\circ} \mathrm{C}\right)$ and $\mathrm{CF}_{4}\left(-128^{\circ} \mathrm{C}\right)$, contribution of $\mathrm{HCl}$ to the initial slight expansion at $-80{ }^{\circ} \mathrm{C}$ was probably low. During warming up to room temperature, the reaction of $\mathrm{AlCl}_{3}$-GIC and the residual aHF caused evolution of the two gases, which lead to the expansion of the GIC. 


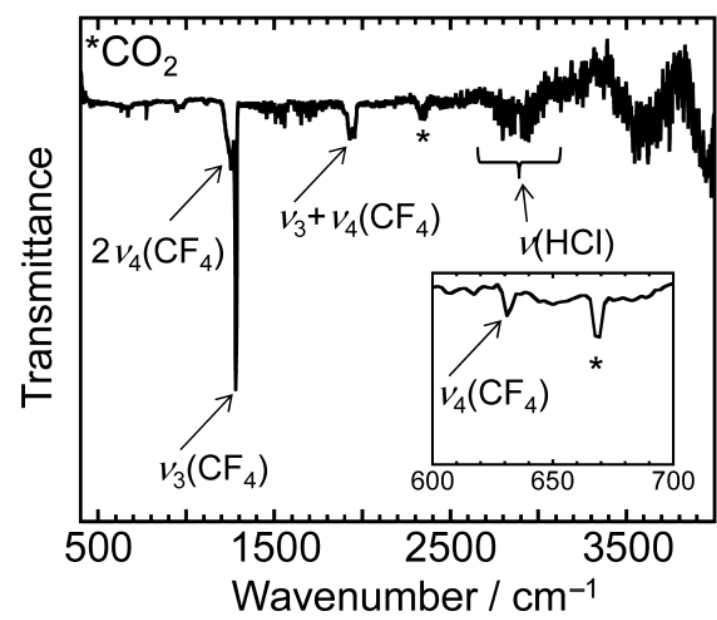

Fig. 6 IR spectrum of the gaseous products obtained by the reaction of $\mathrm{AlCl}_{3}$-GIC and aHF at $25{ }^{\circ} \mathrm{C}$. The inset is the magnified spectrum in the range between 700 and 800 $\mathrm{cm}^{-1}$.

According to elemental analysis, the $\mathrm{C} / \mathrm{F}$ ratio of the products was 3.34 . When the solid products are $\mathrm{C}$ and $\mathrm{AlF}_{3}$ as shown in eq. (1), this $\mathrm{C} / \mathrm{F}$ ratio leads to $x=10.3$ for the starting $\mathrm{C}_{x} \mathrm{AlCl}_{4}$ from the following equation:

$$
\mathrm{C} / \mathrm{F}=(x-0.25) / 3=3.34
$$

The composition, i.e. $\mathrm{C}_{10.3} \mathrm{AlCl}_{4}$, is appropriate as a stage- $1 \mathrm{AlCl}_{3}$ - $\mathrm{GIC}$ according to the previously reported $x$ value from 9 to 10 for $\mathrm{C}_{x} \mathrm{AlCl}_{4}$ [31]. The theoretical weight decrease during the expansion at room temperature is calculated to be 0.30 according to the following equation:

$($ Weight decrease $)=1-\left\{\left(\mathrm{MW}(\mathrm{C})+\mathrm{MW}\left(\mathrm{AlF}_{3}\right)\right) / \mathrm{MW}\left(\mathrm{C}_{10.3} \mathrm{AlCl}_{4}\right)\right\}$ 
where $\mathrm{MW}(\mathrm{X})$ is the molecular weight of $\mathrm{X}\left(\mathrm{MW}\left(\mathrm{C}_{10.3} \mathrm{AlCl}_{4}\right): 292.51, \mathrm{MW}(\mathrm{C}): 12.01\right.$, and $\mathrm{MW}\left(\mathrm{AlF}_{3}\right)$ 83.98). The observed weight loss of $28 \%$ is in good agreement with this theoretical value.

\section{Conclusions}

This study reported the reactivity of $\mathrm{AlCl}_{3}$-GIC and aHF at $25,-30$, and $-80{ }^{\circ} \mathrm{C}$. These reactions resulted in expansion of HOPG and gave information on the reactions of chlorometallate GICs with aHF for the first time. The formation of gaseous products, $\mathrm{HCl}$ and $\mathrm{CF}_{4}$, triggers the present expansion process. The higher reaction temperature resulted in more significant expansion of graphite layers and disordered structures. The present reaction involving the use of aHF may not be applied to a mass production of graphene sheets directly, but the unique reaction pathway would lead to a new method to exfoliate graphite.

\section{Appendix A. Supplementary data.}

Supplementary data associated with this article can be found, in the online version, at http://dx.doi.org/xx.xxxx/j.carbon.xxxx.xx.xxx. 


\section{REFERENCES}

[1] Cai MZ, Thorpe D, Adamson DH, Schniepp HC. Methods of graphite exfoliation. J Mater Chem 2012;22(48):24992-5002.

[2] Chung DDL. Exfoliation of Graphite. J Mater Sci 1987;22(12):4190-8.

[3] Celzard A, Mareche JF, Furdin G. Modelling of exfoliated graphite. Prog Mater Sci 2005;50(1):93-179.

[4] Peigney A, Laurent C, Flahaut E, Bacsa RR, Rousset A. Specific surface area of carbon nanotubes and bundles of carbon nanotubes. Carbon 2001;39(4):507-14.

[5] Geim AK, Novoselov KS. The rise of graphene. Nat Mater 2007;6(3):183-91.

[6] Brownson DAC, Kampouris DK, Banks CE. An overview of graphene in energy production and storage applications. J Power Sources 2011;196(11):4873-85.

[7] Park S, Ruoff RS. Chemical methods for the production of graphenes. Nat Nanotechnol 2009;4(4):217-24.

[8] Yoshida A, Hishiyama Y, Inagaki M. Exfoliated graphite from various intercalation compounds. Carbon 1991;29(8):1227-31.

[9] Malik S, Vijayaraghavan A, Erni R, Ariga K, Khalakhan I, Hill JP. High purity graphenes prepared by a chemical intercalation method. Nanoscale 2010;2(10):2139-43.

[10] Anderson SH, Chung DDL. Exfoliation of intercalated graphite. Carbon 1984;22(3):253-63.

[11] Martin WH, Brocklehurst JE. The thermal expansion behaviour of pyrolytic graphite bromine residue compounds. Carbon 1964;1(2):133-134.

[12] Lv W, Tang DM, He YB, You CH, Shi ZQ, Chen XC, et al.. Low-temperature exfoliated graphenes: vacuum-promoted exfoliation and 
electrochemical energy storage. ACS Nano 2009;3(11):3730-6.

[13] Dresselhaus MS, Dresselhaus G. Intercalation compounds of graphite. Adv Phys 2002;51(1):1-186.

[14] Walter J, Boehm HP. Stability of graphite-intercalation compounds with $\mathrm{TaCl}_{5}$ or $\mathrm{NbCl}_{5}$ against water or dilute acids - a study with XRD, SEM/EDS and electron-microprobe analysis (EMPA). Carbon 1995;33(8):1121-7.

$$
\text { Gualberto GM, Underhill C, Leung SY, Dresselhaus G. Raman and }
$$

infrared-spectra of graphite-AlCl 3 . Phys Rev B 1980;21(2):862-8.

[16] Underhill C, Leung SY, Dresselhaus G, Dresselhaus MS. Infrared and Raman-spectroscopy of graphite-ferric chloride. Solid State Commun 1979;29(11):769-74.

[17] Nakajima T. Fluorine compounds as energy conversion materials. J Fluorine Chem 2013;149:104-11.

[18] Guerin K, Dubois M, Houdayer A, Hamwi A. Applicative performances of fluorinated carbons through fluorination routes: A review. J Fluorine Chem 2012;134:11-7.

[19] Katinonkul W, Lerner MM. Graphite intercalation compounds with large fluoroanions. J Fluorine Chem 2007;128(4):332-5.

[20] Matsumoto K, Hagiwara R. Elimination of $\mathrm{AsF}_{3}$ from anhydrous HF using $\mathrm{AgFAsF}_{6}$ as a mediator. J Fluorine Chem 2011;131(7):805-8.

[21] Peters D, Miethchen R. Symptoms and treatment of hydrogen fluoride injuries. J Fluorine Chem 1996;79(2):161-5.

[22] Nakajima T, Kawaguchi M, Watanabe N. Ternary Intercalation compound of graphite with aluminum fluoride and fluorine. Chem Lett 1981(7):1045-8.

[23] Matsumoto K, Takagi K, Hagiwara R. Electrochemical synthesis of 
graphite-tetrafluoroaluminate intercalation compounds. $\mathrm{J}$ Electrochem Soc 2012;159(11):H876-H80.

[24] Matsuo Y, Nakajima T, Kasamatsu S. Synthesis and spectroscopic study of fluorinated fullerene, C-60. J Fluorine Chem 1996;78(1):7-13.

[25] Watanabe N, Nakajima T, Touhara H. Graphite Fluorides, in Studies in Inorganic Chemistry Amsterdam: Elsevier; 1988.

[26] Kemnitz E, Kohne A, Grohmann I, Lippitz A, Unger WES. X-ray photoelectron and X-ray excited auger electron spectroscopic analysis of surface modifications of chromia during heterogeneous catalyzed chlorine fluorine exchange. J Catal 1996;159(2):270-9.

[27] Mcguire GE, Schweitz.Gk, Carlson TA. Study of core electron binding-energies in some group IIIa, $\mathrm{Vb}$, and $\mathrm{VIb}$ Compounds. Inorg Chem. 1973;12(10):2450-3.

[28] Wang Y, Alsmeyer DC, Mccreery RL. Raman-spectroscopy of carbon materials - Structural basis of observed spectra. Chem Mater 1990;2(5):557-63.

[29] Rank DH, Eastman DP, Rao BS, Wiggins TA. Rotational and vibrational constants of $\mathrm{HCl}^{35}$ and $\mathrm{DCl}^{35}$ Molecules. J Opt Soc Am 1962;52(1):1-5.

[30] McAllister MJ, Li JL, Adamson DH, Schniepp HC, Abdala AA, Liu J, et al.. Single sheet functionalized graphene by oxidation and thermal expansion of graphite. Chem Mater 2007;19(18):4396-404.

[31] Rudorff W, Zeller R. Uber Aluminiumchlorid-Graphit -Einlagerungsverbindungen. Z Anorg Allg Chem 1955;279(3-4):182-93. 


\section{Figure captions}

Fig. 1 A photograph of $\mathrm{EG}(25)$.

Fig. 2 XRD patterns of (a) EG(25), (b) EG(-30), and (c) EG(-80).

Fig. 3 SEM images of (a) EG(25), (b) EG(-30), and (c) EG(-80).

Fig. 4 (a) C1s, (b) Al2 $p_{3 / 2}$, (c) Cl2 $p_{3 / 2}$, and (d) F1s XPS spectra of EG(25), EG(-30), and $\mathrm{EG}(-80)$.

Fig. 5 Raman spectrum of EG(25), EG(-30), EG(-80), and HOPG (basal plane) in the range between 1000 and $2000 \mathrm{~cm}^{-1}$.

Fig. 6 IR spectrum of the gaseous products obtained by the reaction of $\mathrm{AlCl}_{3}$-GIC and aHF at $25{ }^{\circ} \mathrm{C}$. The inset is the magnified spectrum in the range between 700 and 800 $\mathrm{cm}^{-1}$. 